\title{
EVALUATION METHOD OF ALLOWABLE VARIANCE FOR RESULTS OF TRIBOLOGICAL MEASUREMENT ON THE BASIS OF THEIR THE COHERENCE TRENDS AND OF THE COVARIANCE TRENDS \\ METODA OCENY DOPUSZCZALNEJ WARIANCJI DLA WYNIKÓW POMIARÓW TRIBOLOGICZNYCH NA PODSTAWIE PRZEBIEGÓW ICH KOWARIANCJI I KOHERENCJI
}

\author{
Marek Zboiński, Paweł Lindstedt, Maciej Deliś \\ Instytut Techniczny Wojsk Lotniczych \\ e-mail:marek.zboinski@itwl.pl; maciej.delis@itwl.pl
}

\begin{abstract}
This article discusses the possibility of assessing the technical condition of rolling bearings based on tribological tests of oil samples. The problem is to define diagnostic levels, especially when has a relatively small number of measurements (3, 4, 5 etc.). Rating variance of measurements can be performed using the dimensionless factor covariance $\rho(\tau)$ and the dimensionless coherence function $\gamma 2(\omega)$. The set is compact enough when $\rho(\tau)$ and $\gamma 2(\omega)$ will be close enough to oscillate around the value of $1[1,3]$. In summary, it is concluded that the thresholds $\delta, 2 \delta, 3 \delta$ are reliable when $\rho(\tau)$ and $\gamma 2(\omega)$ are greater than $0.7[6]$.
\end{abstract}

Keywords: ball bearing, the diagnostic signals, diagnostic level, the variance of data, covariance, coherence

Streszczenie: Artykut omawia możliwości oceny stanu technicznego tożysk tocznych na podstawie badań tribologicznych próbek oleju. Problemem jest wyznaczenie progów diagnostycznych, szczególnie gdy dysponuje się stosunkowo mała liczba pomiarów (3, 4, 5 itp.). Ocena wariancji wyników pomiarów może być przeprowadzona $z$ wykorzystaniem bezwymiarowego wspótczynnika kowariancji $\rho(\tau)$ i bezwymiarowej funkcji koherencji $\gamma 2(\omega)$. Zbiór będzie dostatecznie zwarty gdy $\rho(\tau)$ i $\gamma 2(\omega)$ będa dostatecznie blisko oscylować wokót wartości 1 [1, 3]. W podsumowaniu stwierdza się, że progi $\delta, 2 \delta, 3 \delta$ sq wiarygodne gdy $\rho(\tau)$ i $\gamma 2(\omega)$ wynosza więcej niż 0,7 [6].

Stowa kluczowe: łożysko toczne, sygnały diagnostyczne, próg diagnostyczny, wariancja zbioru, kowariancja, koherencja 
Evaluation method of allowable variance for results of tribological measurement. Metoda oceny dopuszczalnej wariancji dla wyników pomiarów tribologicznych...

\section{Wstęp}

Diagnostyka techniczna (wzorując się na diagnostyce medycznej) a priori wszystkie obiekty techniczne traktuje indywidualnie, bowiem nie ma (i być nie może, ze względu na istniejące odchyłki materiałowe, technologiczne, obsługowe) dwóch, trzech i wielu identycznych: samolotów, silników, pomp, łożysk, łopatek turbiny czy sprężarki. Konsekwencją tego stanu rzeczy jest coraz bardziej widoczna potrzeba szukania progów diagnostycznych dla każdego indywidualnego obiektu technicznego. Dotyczy to szczególnie takich obiektów technicznych jak łopatki lub łożyska. Indywidualizacja obiektów technicznych tego samego typu powoduje, że wyniki diagnostyczne nie są liczne. Dotyczy to przede wszystkim chwili, gdy rozpoczynamy proces diagnostyczny i gdy rozpoczyna się indywidualne diagnozowanie obiektu $\mathrm{z}$ danego zbioru obiektów. Wtedy przeważnie dysponuje się małą liczbą ( $3,4,5$ itp.) pomiarów, co powoduje, że wymagają one szczególnie dokładnej obróbki opartej na korelacji i splocie ciągów uzyskanych pomiarów.

\section{Tribologiczna metoda diagnozowania}

W procesie eksploatacji układy łożyskowania przeważnie diagnozowane są jednocześnie trzema metodami diagnozowania $[6,10]$ :

- funkcjonalna metoda diagnozowania (sygnałem diagnostycznym jest czas wybiegu ułożyskowanego wirnika)

- wibroakustyczna metoda diagnozowania (sygnałami diagnostycznymi są: amplituda drgań - $A$, prędkość drgań - $\dot{A}$ i przyśpieszenie - $\ddot{A}$ )

- tribologiczna metoda diagnozowania (sygnałami diagnostycznymi są: $K P Z$ - przyrost koncentracji produktów zużywania między kolejnymi pomiarami, $I Z$ - intensywność zużywania)

Szczególnego znaczenia ze względu na dużą dokładność oceny stanu technicznego układów łożyskowania nabiera tribologiczna metoda diagnozowania. Wykorzystywane sygnały $K P Z$ i $I Z$ (wyznaczane są w znanych okresach czasu $\Delta \Theta$ między kolejnymi pomiarami) obliczane są z następujących zależności $[4,10]$ :

$$
\begin{gathered}
K P Z=\left(D_{L}-D_{S}\right), \\
I Z=\left(D_{L}^{2}-D_{S}^{2}\right),
\end{gathered}
$$

gdzie:

$D_{L}$ - liczba cząstek większych od $5 \mu \mathrm{m}$;

$D_{S}$ - liczba cząstek małych o wymiarach $0,1 \div 2 \mu \mathrm{m}$.

Przykładowe wyniki diagnozowania 2 silników turbinowych przedstawiono w Tabeli 1. $[8,9]$ 
Marek Zboiński, Pawet Lindstedt, Maciej Deliś

Tabela 1. Wybrane wyniki z diagnozowania uktadów tożyskowania 2 silników Allison 250.

\begin{tabular}{|c|c|c|c|c|c|c|}
\hline Lp. & Nalot & $\begin{array}{c}\text { Okres } \\
\text { diagnostyczny } \\
\Delta \theta\end{array}$ & $K P Z_{1}$ & $K P Z_{2}$ & $I Z_{1}$ & $I Z_{2}$ \\
\hline 1 & 191 & 100 & 1,5 & 3,9 & 0,15 & 0,39 \\
\hline 2 & 297 & 106 & 7,0 & 5,5 & 4,20 & 1,65 \\
\hline 3 & 395 & 98 & 2,5 & 3,7 & 0,25 & 1,85 \\
\hline 4 & 500 & 105 & 7,1 & 5,9 & 3,55 & 0,59 \\
\hline 5 & 600 & 100 & 4,2 & 4,1 & 3,36 & 0,41 \\
\hline 6 & 698 & 98 & 5,3 & 5,2 & 0,53 & 1,04 \\
\hline 7 & 798 & 100 & 19,8 & 8,4 & 23,8 & 1,68 \\
\hline 8 & 879 & 81 & 10,5 & 12,7 & 7,35 & 11,40 \\
\hline 9 & 891 & 12 & 3,0 & 6,4 & 0,60 & 2,56 \\
\hline 10 & 912 & 21 & 7,4 & 6,1 & 10,40 & 1,83 \\
\hline $\begin{array}{l}\text { Wartość } \\
\text { srednia: }\end{array}$ & 81,8 & 6,83 & 6,19 & 4,26 & 2,34 \\
\hline
\end{tabular}

Chwilowa wartość sygnału $K P Z_{i}$ i $I Z_{i}$ zależy od zmiany stanu technicznego (zużycie łożyska), lecz także od długości okresu użytkowania $\Delta \Theta_{i}$. Dane umieszczone $\mathrm{w}$ Tabeli 1 są podstawą do wyznaczenia progów diagnostycznych $\mu+\delta ; \mu+2 \delta ; \mu+3 \delta$ ( $\mu$ - średnia pomiarów; $\delta$ - odchylenie standardowe) dla każdego silnika oddzielnie. Problem komplikuje się gdy dysponujemy małą liczbą pomiarów (np. 3, 4, ..). Stąd wynika potrzeba badania spójności posiadanego zbioru pomiarów $[1,5,14]$. Można do tego wykorzystać bezwymiarową funkcję kowariancji $\rho^{2}(\tau)$ i bezwymiarową funkcję koherencji $\gamma^{2}(\omega)$.

\section{Podstawy teoretyczne korelacji sygnałów $[1,3,11]$}

W przypadku badania progów diagnostycznych rozpatruje (analizuje) się ciągi liczb wynikające z odpowiednich pomiarów. Są to ciągi charakteryzujące otoczenie (np. liczba przepracowanych godzin, ciąg $-x$ oraz ciąg liczb wynikający z pomiaru sygnału $K P Z$ - ciąg $y$ ). Mamy zatem dwa ciągi liczb: $\left\{x_{0}, x_{1}, x_{2}, x_{3}, \ldots\right\}$ oraz $\left\{y_{0}, y_{1}\right.$, $\left.y_{2}, y_{3}, \ldots\right\}$ Związek między tymi ciągami może być określany za pomocą ich korelacji:

$$
\begin{gathered}
\left\{x_{0}, x_{1}, \ldots, x_{m}\right\} \otimes\left\{x_{0}, x_{1}, \ldots, x_{m}\right\}=\left\{x_{0} x_{0}, x_{0} x_{1}+x_{1} x_{0}, \ldots, x_{m} x_{n}\right\}, \\
\left\{y_{0}, y_{1}, \ldots, y_{m}\right\} \otimes\left\{y_{0}, y_{1}, \ldots, y_{m}\right\}=\left\{y_{0} y_{0}, y_{0} y_{1}+y_{1} y_{0}, \ldots, y_{m} y_{n}\right\}, \\
\left\{x_{0}, x_{1}, \ldots, x_{m}\right\} \otimes\left\{y_{0}, y_{1}, \ldots, y_{m}\right\}=x_{0} y_{0}, x_{0} y_{1}+x_{1}
\end{gathered}
$$

gdzie: $\otimes$ - korelacja sygnałów. 
Evaluation method of allowable variance for results of tribological measurement. Metoda oceny dopuszczalnej wariancji dla wyników pomiarów tribologicznych...

Obliczenie korelacji ciągu liczb jest w praktyce prostym do wykonania działaniem, co ilustruje rys. 1 .

\begin{tabular}{ccc} 
& 1 & \\
& 1 & \\
2 & 2 & 4 \\
2 & & 6 \\
3 & & 10 \\
3 & & 11 \\
4 & & 14 \\
& & 7 \\
& $\downarrow$ & 4 \\
\hline 14 & 4 & 56
\end{tabular}

Rys. 1 Schemat obliczenia korelacji ciagu liczb

sygnałów z badań diagnostycznych (zbiorów $\{2,2,3,3,4\}$ i $\{1,1,2\}$ )

Na rys. 1 przedstawiono korelację ciągu liczb $\{2,2,3,3,4\} \otimes\{1,1,2\}=\{4,6,10,11,14,7,4\}$. Ciąg $\{1,1,2\}$ został zapisany od góry do dołu i jest przesuwany w dół, aż do pojawienia się kolejnej pary wartości ciągu pierwszego i drugiego. Liczba wyrazów ciągu korelacji jest równa sumie liczby wyrazów mnożonych ciągów mniejsza o jeden wyraz (5+3)-1=7 wyrazów. Większa liczba wyrazów wynikających $z$ liczby pomiarów otoczenia i sygnałów diagnostycznych oraz możliwość tworzenia własnych ciągów liczb korelacji dla sygnałów otoczenia $C_{x}$ i sygnałów diagnostycznych $C_{y}$, a także tworzenia wzajemnych korelacji $C_{x y}$ ciągu liczb tychże sygnałów daje duże możliwości w interpretacji wyników badań diagnostycznych. Można wzorując się na standardowej analizie sygnałów ustalić miary relacji między sygnałami: kowariancję między sygnałami otoczenia $x$ i diagnostycznych $y$ w postaci:

$$
\rho_{x y}(\tau)=\frac{C_{x y}(\tau)}{\sqrt{C_{x} C_{y}}} \leq 1 \quad C_{x m a k s} \quad C_{y m a k s},
$$

gdzie:

$$
\begin{aligned}
& C_{x}=R_{x}(\tau)-\mu_{x}^{2} \\
& C_{y}=R_{y}(\tau)-\mu_{y}^{2} \\
& C_{x y}=R_{x y}(\tau)-\mu_{x} \mu_{y}
\end{aligned}
$$

$\mu$ to średnia wartość odpowiednich ciągów skorelowanych liczb. 
Stwierdza się dalej, że: jeżeli funkcja kowariancji jest większa od zera, ale mniejsza od jedności to wtedy występuje jeden z trzech możliwych przypadków $[1,3,5,11]$ :

1) wyniki pomiarów są obarczone błędem wynikających $\mathrm{z}$ obecności szumów zewnętrznych;

2) układy wiążący sygnały $x$ i $y$ są nieliniowe;

3) sygnał wyjściowy y jest wynikiem nie tylko działania sygnału $x$, lecz również innych sygnałów wyjściowych.

\section{Podstawy teoretyczne splotu ciągu pomiarów $[1,3,11]$}

W tym przypadku także analizowane są ciągi liczb charakteryzujące otoczenie $x$ i ciąg liczb charakteryzujący sygnał $K P Z$.

$$
\begin{gathered}
\left\{x_{0}, x_{1}, \ldots, x_{m}\right\} *\left\{x_{0}, x_{1}, \ldots, x_{m}\right\}=\left\{x_{0} x_{0}, x_{0} x_{1}+x_{1} x_{0}, \ldots, x_{m} x_{n}\right\}, \\
\left\{y_{0}, y_{1}, \ldots, y_{m}\right\} *\left\{y_{0}, y_{1}, \ldots, y_{m}\right\}=\left\{y_{0} y_{0}, y_{0} y_{1}+y_{1} y_{0}, \ldots, y_{m} y_{n}\right\}, \\
\left\{x_{0}, x_{1}, \ldots, x_{m}\right\} *\left\{y_{0}, y_{1}, \ldots, y_{m}\right\}=x_{0} y_{0}, x_{0} y_{1}+x_{1},
\end{gathered}
$$

gdzie: * - splot sygnałów.

Obliczenie splotu ciągu liczb jest proste, co ilustruje rysunek 2.

\begin{tabular}{ccc} 
& 2 & \\
& 1 & \\
2 & 1 & 2 \\
2 & & 4 \\
3 & & 9 \\
3 & & 10 \\
4 & & 13 \\
& & 10 \\
& $\downarrow$ & 8 \\
\hline
\end{tabular}

$14 \quad 4 \quad 56$

Rys. 2 Schemat obliczenia splotu ciagu liczb sygnałów

$z$ badań diagnostycznych (zbiorów $\{2,2,3,3,4\}$ i $\{1,1,2\}$ )

Na rysunku 2 przedstawiono splot ciągu liczb $\{2,2,3,3,4\} *\{1,1,2\}$. Ciąg $\{1,1,2\}$ w danym przypadku zapisany jest od dołu do góry i przesuwany jest w dół, aż do pojawienia się kolejnych par ciągu pierwszego i drugiego. Tu także wzorując się na standardowej analizie sygnałów można ustalić miary relacji między sygnałami: koherencję między sygnałami otoczenia $x$ i diagnostycznymi $y$. 
Evaluation method of allowable variance for results of tribological measurement. Metoda oceny dopuszczalnej wariancji dla wyników pomiarów tribologicznych...

Tu interpretacja jest prosta - zbiór jest skupiony gdy $\gamma_{x y}^{2}(\omega) \approx 1$. Zużycie jest prawidłowe gdy $|A|^{2}(\omega)<<1$. [1, 3, 10, 11]

$$
\begin{gathered}
\gamma_{x y}^{2}(\omega)=\frac{\left|S_{x y}\right|^{2}}{S_{x} S_{y}} \leq 1, \\
|A|^{2}(\omega)=\frac{S_{y}}{S_{x}}<<1,
\end{gathered}
$$

Należy podkreślić, że stosując koherencję sygnałów zatem ich porównywanie w dziedzinie częstotliwości otrzymuje się dwa precyzyjne warunki o ich porównywania: $\gamma_{x y}^{2}(\omega)$ i $A^{2}(\omega)$

\section{Ocena stanu skupienia sygnałów z badań diagnostycznych}

Dla silnika 1 (Tabela 1) ustala się wartości sygnału otoczenia $x$, którym są okresy diagnostyczne $\Delta \Theta$ oraz wartości sygnałów diagnostycznych KPZ1. Dla 3 pomiarów są to ciągi liczb: $\{100,106,98\}$ i $\{1.5,7,2.5\}$. Następnie wyznacza się iloczyny korelacji $R_{x y i}, R_{x i}$, $R_{y i}$ oraz iloczyny kowariancji $C_{x y i}, C_{x i}$, i $C_{y i}$.

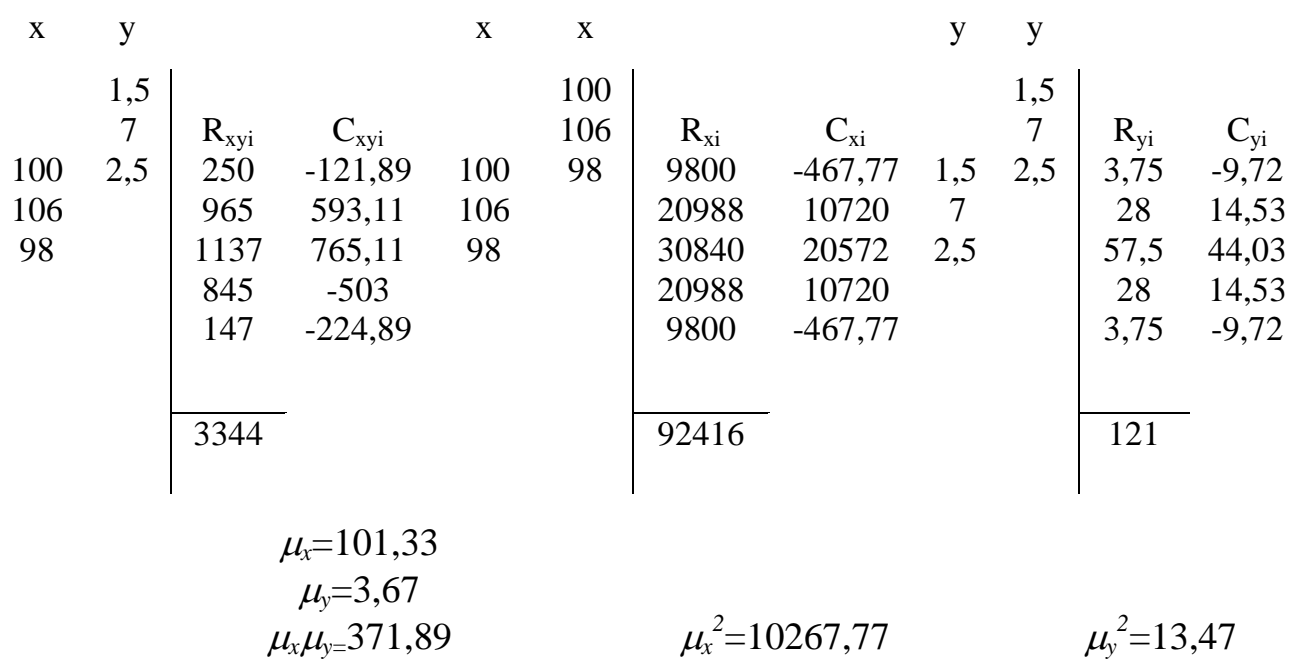

Ostatecznie otrzymuje się przebiegi ciągu funkcji wzorowanej na współczynniku korelacji $\rho_{x y i}$ silnika 1:

$$
\rho_{x y i}=\frac{C_{x y i}}{\sqrt{C_{x i m a k s} C_{y i m a k s}}},
$$


Marek Zboiński, Pawet Lindstedt, Maciej Deliś

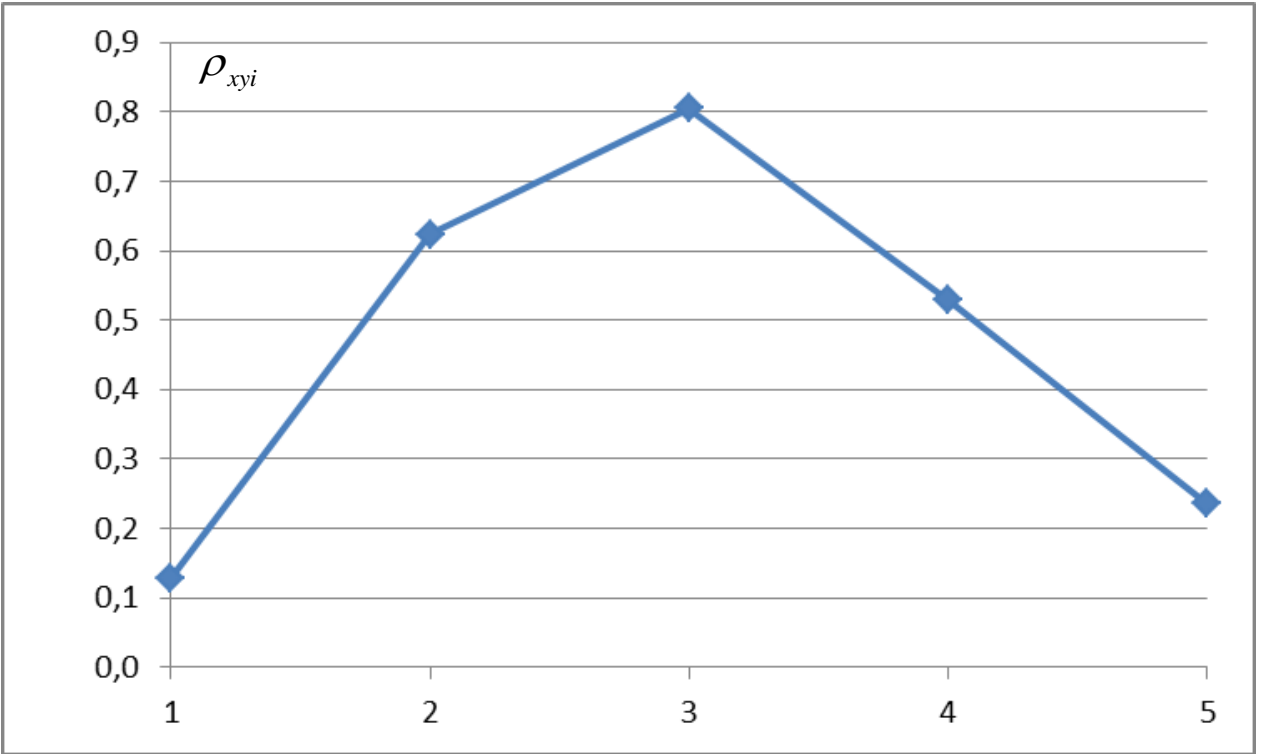

Rys. 3 Przebieg funkcji kowariancji $\rho_{x y i}$ dla silnika 1

W podobny sposób na podstawie danych - Tabela 1 - dla silnika 2 ustala się sygnały otoczenia $x$ i diagnostyczne $y$. Dla 3 pomiarów są to ciągi liczb: $\{100,106,98\}$ i $\{3.9,5.5,3.7\}$. Następnie wyznacza się $C_{x y i}, C_{x i}$, i $C_{y i}$ oraz poszukiwane $\rho_{x y i}$ dla silnika 2 (rys. 4)

$\mathrm{x} \quad \mathrm{y}$

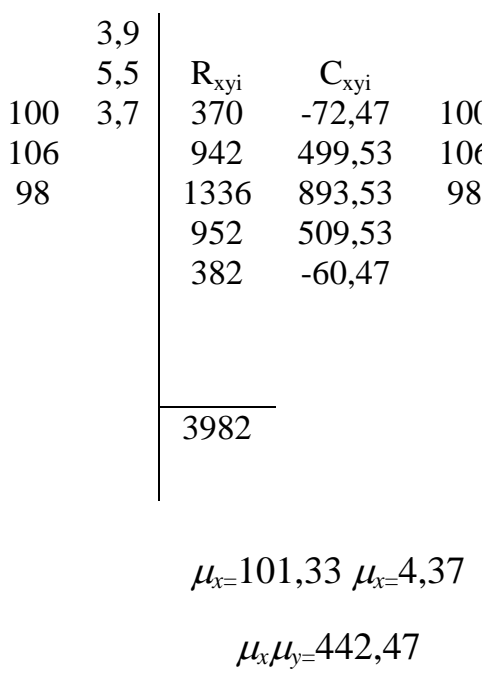

$\mathrm{x}$

$\mathrm{x}$
100
106
98

\begin{tabular}{cccc|cc}
\multicolumn{5}{c}{$\mathrm{y}$} & $\mathrm{y}$ \\
& & & 3,9 & & \\
$\mathrm{R}_{\mathrm{xi}}$ & $\mathrm{C}_{\mathrm{xi}}$ & & 5,5 & $\mathrm{R}_{\mathrm{yi}}$ & $\mathrm{C}_{\mathrm{yi}}$ \\
9800 & - & 3,9 & 3,7 & 14,43 & $-4,67$ \\
20988 & 467,77 & 5,5 & & 41,80 & 22,7 \\
30840 & 10720 & 3,7 & & 59,14 & 40,04 \\
20988 & 20572 & & & 41,80 & 22,7 \\
9800 & 10720 & & & 14,43 & $-4,67$ \\
& - & & & & \\
& 467,77 & & & & \\
& & & & & \\
\cline { 1 - 1 } 92416 & & & & 171,6 &
\end{tabular}

$\mu_{x}=101,33$

$\mu_{y}=4,37$

$\mu_{x}^{2}=10267,77$

$\mu_{y}^{2}=19,1$ 
Evaluation method of allowable variance for results of tribological measurement. Metoda oceny dopuszczalnej wariancji dla wyników pomiarów tribologicznych...

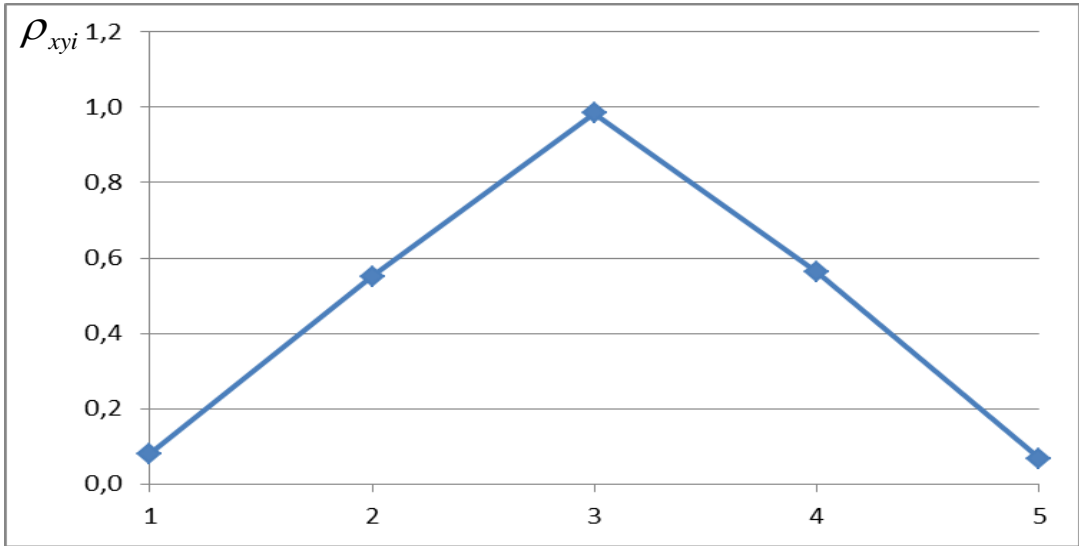

Rys. 4 Przebieg funkcji kowariancji $\rho_{x y i}$ dla silnika 2

Wyniki weryfikowane są na podstawie ciągu liczb wynikających ze splotu ciągu liczb $\{100,106,98\}$ i $\{1.5,7,2.5\}$ dla silnika 1 i silnika 2 .

Ze splotu ciągu licz otrzymuje się ciągi liczb $\hat{S}_{x y i}, \hat{S}_{x i}$ i $\hat{S}_{y i}$ w domenie czasu $t$. Ten ciąg zostaje przekształcony w ciąg liczb $S_{x y i}, \quad S_{x i}$ i $S_{y i}$ w domenie częstotliwości $\omega$ wg zależności:

$$
\begin{gathered}
S_{i}^{2}(\omega)=\left(\hat{S}_{i}^{2}+\mu_{i}^{2}\right) \delta(\omega) \\
\hat{S}_{i}=\hat{S}_{i}+\mu_{i}^{2}
\end{gathered}
$$

gdzie:

$S_{i}^{2}\left(S_{x y i}, S_{x i}, S_{y i}\right)$ - ciąg liczb moce wzajemne i własne splatanych sygnałów;

$\hat{S}_{i}^{2}$ - składowa fluktuacyjna ciągu liczb mocy wzajemnej i własnej splatanych sygnałów;

$\mu_{i}^{2}$ - średnia wartość ciągu liczb mocy splatanych sygnałów;

\begin{tabular}{|c|c|c|c|c|c|c|c|c|c|c|}
\hline 2,5 & & & & 98 & & & & 2,5 & & \\
\hline 7 & $S_{x y i}$ & $\hat{S}_{x y i}$ & & 106 & $S_{x i}$ & $\hat{S}_{x i}$ & & 7 & $S_{y i}$ & $\hat{S}_{y i}$ \\
\hline 1,5 & 150 & -519 & 100 & 100 & 10000 & & 1,5 & 1,5 & 2,25 & $-22,0$ \\
\hline 106 & 859 & 190 & 106 & & 21200 & -8483 & 7 & & 21 & $-3,2$ \\
\hline 98 & 1139 & 470 & 98 & & 30836 & 2717 & 2,5 & & 56,5 & 32,3 \\
\hline & 951 & 282 & & & 20776 & 12353 & & & 35 & 10,8 \\
\hline & 245 & -424 & & & 9604 & 2293 & & & 6,25 & $-18,0$ \\
\hline & 3344 & & & & 92416 & -8879 & & & 121 & \\
\hline & $\begin{array}{l}=669 \\
47561\end{array}$ & $\begin{array}{l}10^{2} \\
48 * 10^{5}\end{array}$ & & & $\begin{aligned} \mu_{S x} & =1 \\
\mu_{S x}{ }^{2} & =3\end{aligned}$ & $\begin{array}{l}83=18, \\
621289\end{array}$ & & & & $\begin{array}{l}y=24,2 \\
y^{2}=586\end{array}$ \\
\hline
\end{tabular}

Dla silnika 1 mamy: 
Stąd otrzymuje się przebiegi koherencji $\gamma_{x y i}^{2}(\omega)$ i $|A|_{i}^{2}(\omega)$ dla silnika 1

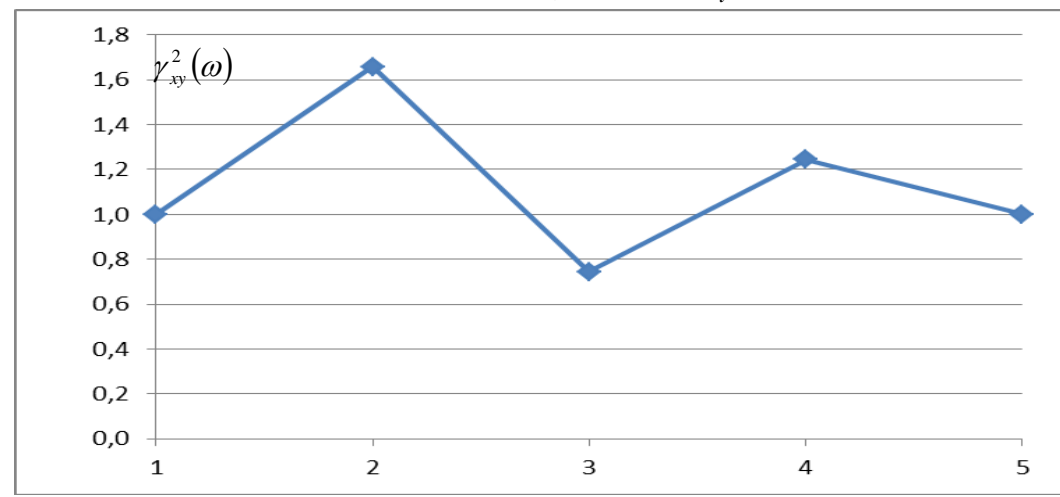

Rys. 5 Przebieg funkcji koherencji $\gamma_{x y i}^{2}(\omega)$ dla silnika 1

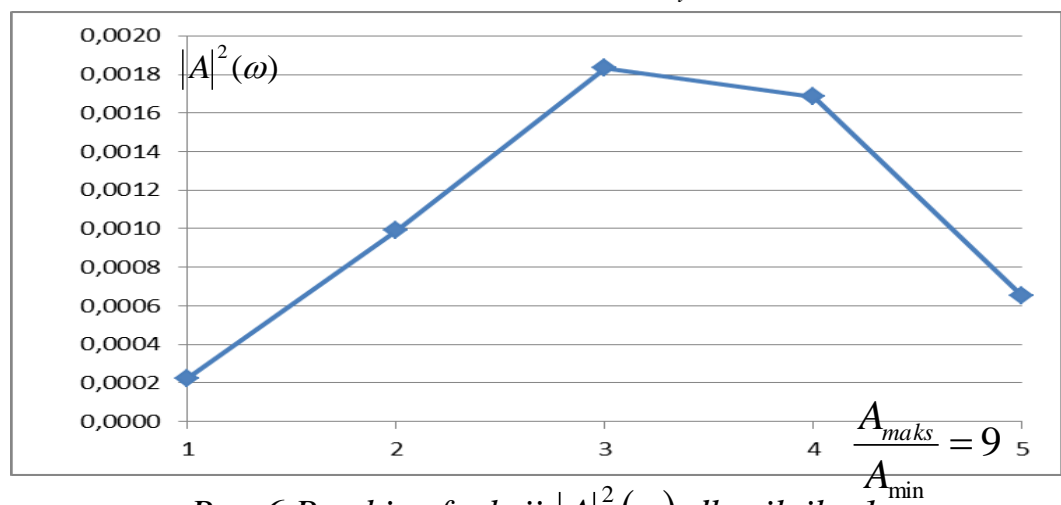

Rys. 6 Przebieg funkcji $|A|_{i}^{2}(\omega)$ dla silnika $1_{\text {min }}$

Dla silnika 2 sploty ciągów liczb są następujące:

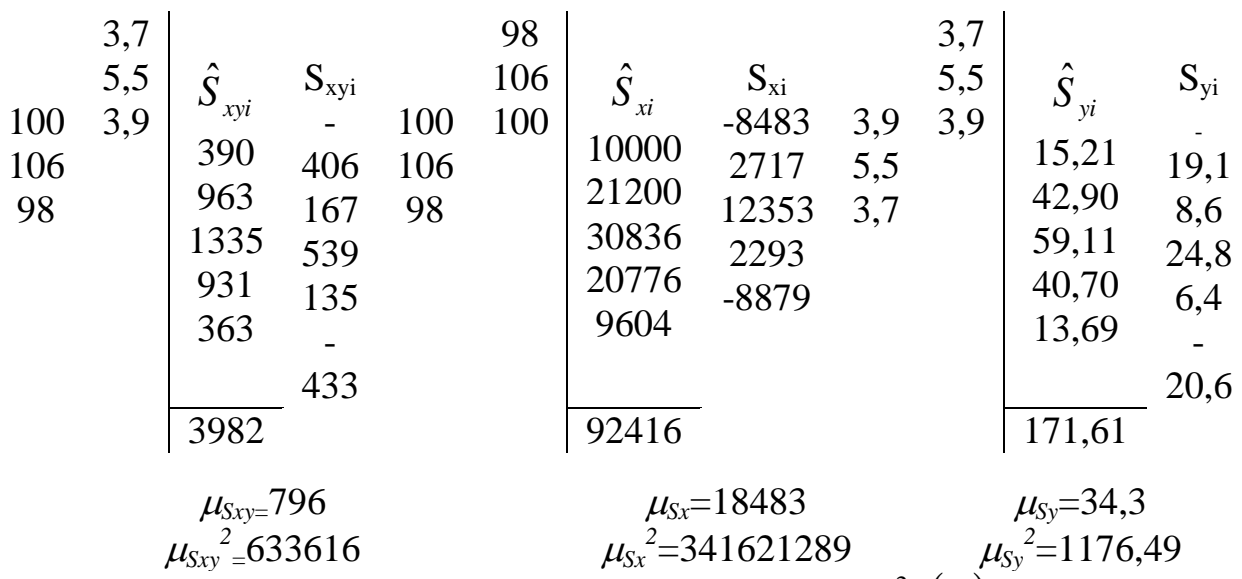

Stąd otrzymuje się przebiegi ciągów koherencji $\gamma_{x y i}^{2}(\omega)$ i wzmocnienia amplitudowego $|A|_{i}^{2}(\omega)$, które przedstawiono na rysunku 7 oraz rysunku 8 . 
Evaluation method of allowable variance for results of tribological measurement. Metoda oceny dopuszczalnej wariancji dla wyników pomiarów tribologicznych...

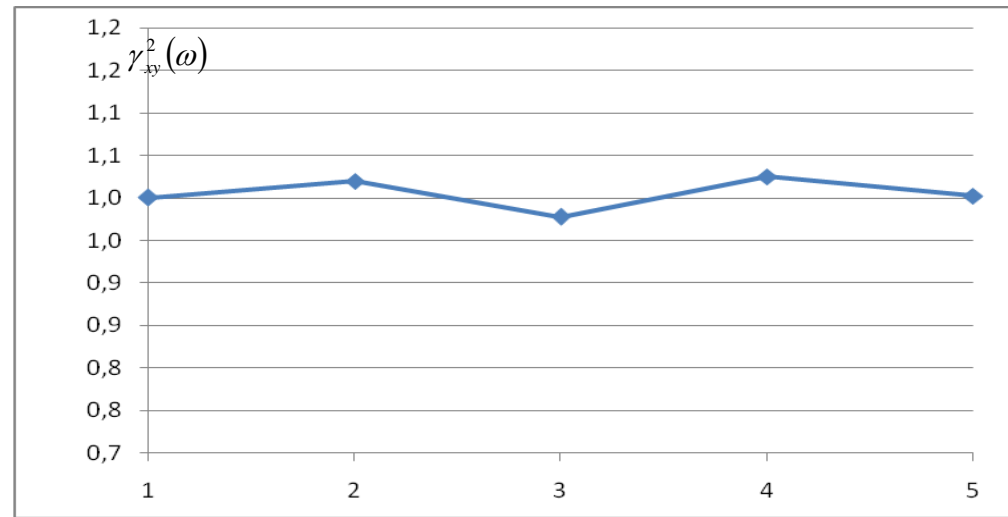

Rys. 7 Przebieg funkcji koherencji $\gamma_{x y i}^{2}(\omega)$ dla silnika 2

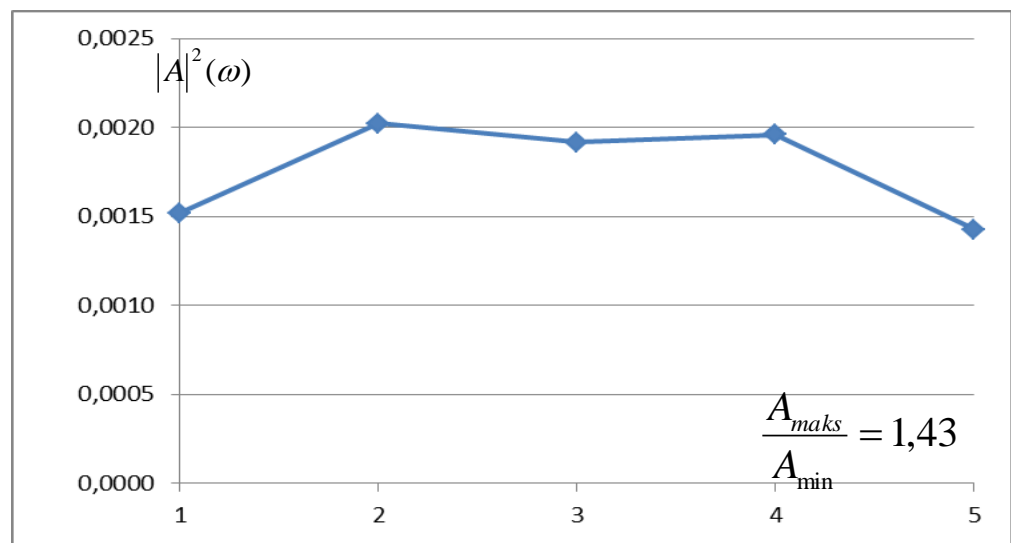

Rys. 8 Przebieg funkcji $A_{i}^{2}(\omega)$ dla silnika 2

Stąd wniosek, że diagnoza silnika 1 jest obarczona większym błędem niż diagnoza silnika 2. Oznacza to także, że ocena stanu technicznego silnika 1 (oceniany na podstawie 3 pomiarów) jest na pewno słabsza od oceny stanu technicznego silnika 2, co też jest zgodne $\mathrm{z}$ intuicją eksperta. Wniosek ten pokrywa się z bezpośrednią analizą progów diagnostycznych (silnik 1 progi obarczone większym błędem od progów silnika 2). Zbiór pomiarów silnika 2 jest bardziej skupiony zatem wyznaczone progi są bardziej wiarygodne $[2,7,8,12,14]$.

\section{Podsumowanie}

Wyznaczenie progu diagnostycznego jest podstawowym warunkiem dokładności diagnozowania. Bez prawidłowo wyznaczonego progu diagnostycznego nie można diagnozować. Jest to jednakże warunek konieczny ale niewystarczający szczególnie wtedy gdy dysponuje się małym zbiorem pomiarów (3, 4, itp.), a problem ten zawsze występuje, gdy rozpoczynamy proces indywidualizacji diagnozowanych obiektów. Środkiem pomocniczym w weryfikacji diagnozy na 
podstawie wyznaczonych progów diagnostycznych mogą być wskaźniki korelacji między sygnałami:

- kowariancji czasowej;

- współczynnika wzmocnienia.

One pozwalają doprecyzować diagnozę wstępnie wypracowaną na podstawie analizy małej liczby pomiarów chwilowych progów diagnostycznych.

Dodatkowo progi diagnostyczne bazujące na odchyleniu standardowym $\delta$ powinny być zweryfikowane progami wyznaczonymi na podstawie zasady LindebergaLevy'ego [6, 7]:

$$
d_{d o p}=m \mu+a \delta \sqrt{m}, m=\frac{\theta_{\text {maks }}}{\Delta \theta_{s r}}
$$

gdzie:

$d_{d o p}$ - wartość dopuszczalna dla m wartości parametrów, $\mu$ - średnia wartość parametrów, $\delta$ - odchylenie standardowe, $a$ - współczynnik wagi (przyjmuje wartości 1,2,3).

Bieżącą wartość progu diagnostycznego wylicza się z zależności:

$$
d_{p r i}=i \mu+a \delta \sqrt{i}
$$

oraz z zależności

$$
d_{\text {prdopi }}=\frac{d_{d o p} \theta_{i}}{\theta_{\text {maks }}}
$$

gdzie: $d_{p r i}$ - bieżąca wartość progu, $i$ - liczba wykonanych pomiarów, $d_{p r d o p i}$ bieżąca wartość progu wyliczonej z wartości dopuszczalnej $d_{d o p}$ uwzględniającej podawaną przez producenta wartość $\theta_{\text {maks }}$ (resurs). Bada się położenie wartości $d_{p r i}$ względem wartości $d_{\text {prdopi }}$

Ostatecznie stwierdza się, że przyjęcie w procesie diagnozowania odpowiedniego progu diagnostycznego wymaga wszechstronnej analizy zbioru pomiarów, a także dużej wiedzy eksperta - diagnosty.

\section{Projekt zostal sfinansowany ze środków Narodowego Centrum Nauki przyznanych na podstawie decyzji nr 5186/B/T02/2011/40.}

\section{Literatura}

[1] Bendat J. S., Piersol A. G.: Metody analizy i pomiaru sygnałów losowych, PWN, Warszawa 1968.

[2] Borowczyk H.: Model kompleksowego systemu diagnostycznego płatowca i zespołu napędowego statku powietrznego, V Międzynarodowa Konferencja AIRDIAG'97, Wyd. ITWL, Warszawa 1997.

[3] Bracewell R.: Przekształcenie Fouriera i jego zastosowania, WNT, Warszawa 1968.

[4] Deliś M., Diagnosis of aircraft engines tribological systems with the ferrography method, Journal of KONBiN, 2011, Nr 1, s. 67-74.

[5] Franks L.E., Teoria sygnałów, WNT, Warszawa 1975.

[6] de Larminat P., Thomas Y.: Automatyka: układy liniowe; Sygnały i układy. Warszawa : Wydaw. Nauk.-Techn., 1983. 
Evaluation method of allowable variance for results of tribological measurement. Metoda oceny dopuszczalnej wariancji dla wyników pomiarów tribologicznych...

[7] Leitner, R., Zacharski, J., Zarys matematyki wyższej, Wydawnictwa Naukowo-Techniczne, Warszawa 2005.

[8] Lindstedt, P., Sudakowski, T., The Method of Assessment of Suitability of the Bearing System Based on Parameters of Technical and Adjustment State, Mechatronic systems and materials V, Solid State Phenomena, Trans-Tech Publications, pp. 73-78, Durnten-Zurich 2013.

[9] Magier J., Lindstedt P.: Koncepcja kompleksowej metody diagnozowania układu łożyskowania silnika Allison 250-C20B, VII Międzynarodowa Konferencja AIRDIAG'2001, Wyd. ITWL, Warszawa 2001.

[10] Magier J.: Diagnozowanie układów łożyskowania turbinowego silnika śmigłowcowego na podstawie przekroczeń progów diagnostycznych sygnałów funkcjonalnych, tribologicznych i wibroakustycznych, Rozprawa doktorska, Wyd. ITWL, Warszawa 2004.

[11] Osiowski J.: Zarys rachunku operatorowego, WNT, Warszawa 1981.

[12] Sołodnikow W.W., Dynamika statyczna liniowanych układów sterownia automatycznego, WNT, Warszawa 1964.

[13] Szabatin J.: Podstawy teorii sygnałów, WKŁ, Warszawa 2000 .

[14] Zboiński M., Lindstedt P., Kotlarz I.: Stałe i aktualizowane statystyczne tribologiczne progi diagnostyczne $\mathrm{i}$ ich znaczenie w procesie bieżącej oceny stanu technicznego układu łożyskowania silnika lotniczego, Journal of KONBIN 1(17) 2011, Warszawa 2011.

[15] Zboiński M.: Badania diagnostyczne układów tribologicznych w statkach powietrznych, w: Problemy badań i eksploatacji techniki lotniczej, red. Lewitowicz J., Loroch L., Manerowski J., t. VI, Wyd. ITWL, Warszawa 2007.

[16] Zboiński, M., Lindstedt, P., Deliś, M., Opportunities of evaluation diagnostic test results of roller bearings from signals correlation of bearing and its environment, Journal of KONBIN Vol. 22, pp. 109-118, Warszawa 2012.

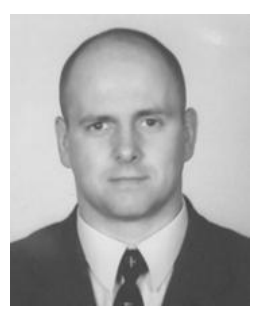

dr inz. Marek Zboiński - adiunkt, kierownik Akredytowanego Laboratorium Diagnostyki Systemów Tribologicznych w Instytucie Technicznym Wojsk Lotniczych. Prace dotycza diagnozowania silników lotniczych, układów tożyskowania metodami zużyciowymi.

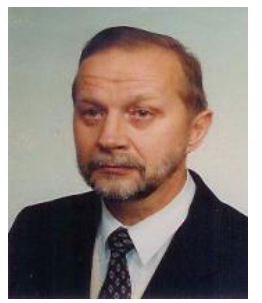

prof. dr hab. ini. Pawel Lindstedt - profesor Politechniki Biatostockiej, profesor nadzwyczajny Instytutu Technicznego Wojsk Lotniczych. Tematyka badawcza: budowa i eksploatacja maszyn, automatyka stosowana, diagnostyka i niezawodność maszyn. Prace dotycza diagnozowania silników lotniczych, układów tożyskowania metodami funkcjonalnymi, wibroakustycznymi i zużyciowymi.

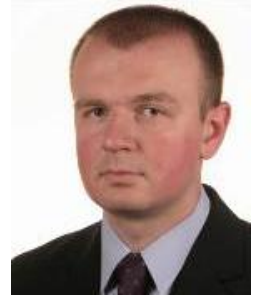

dr inż. Maciej Deliś - starszy inżynier w Pracowni Diagnostyki Systemów Tribologicznych Zakładu Silników Lotniczych ITWL. 